\section{SAT0388 FACTORS ASSOCIATED WITH THE PERSISTENCE OF ARTICULAR SYMPTOMS IN PATIENTS WITH CHIKUNGUNYA FEVER - CHIKBRASIL COHORT}

C. Marques ${ }^{1}$, A. Duarte ${ }^{1}$, A. Dantas ${ }^{1}$, A. Ranzolin ${ }^{1}$, N. Cavalcanti ${ }^{1}$, M. Medeiros ${ }^{2}$ M. Bezerra ${ }^{2}$, V. Marques ${ }^{2}$, L. Rocha $\mathrm{Jr}^{3}$, P. Melo ${ }^{3}$, L. Valadares ${ }^{4}$, C. da Fonte ${ }^{4}$, E. Freire ${ }^{5}$, A.K. Melo ${ }^{5}$, R.A. Ocea ${ }^{6}{ }^{1}$ Internal Medicine, Universidade Federal de Pernambuco, Recife; ${ }^{2}$ Rheumatology, Universidade Federal do Ceará, Fortaleza; ${ }^{3}$ Internal Medicine, Instituto de Medicina Integral Professor Fernando Figueira IMIP; ${ }^{4}$ Internal Medicine, Hospital Getulio Vargas, Recife; ${ }^{5}$ Internal Medicine, Universidade Federal da Paraíba, João Pessoa; ${ }^{6}$ Internal Medicine, Universidade Federal de Sergipe, Aracaju, Brazil

Background: Chikungunya Fever (CHIK) may evolve chronically with joint impairment, often disabling, which leads to a functional and quality of life impact. The CHIK outbreak in Brazil began in 2015, reaching its peak in 2016, particularly in the Northeast of the country, with 235136 reported cases. Since this is the first epidemic of CHIK in Brazil, data on persistent post-acute joint disease are scarce, and this knowledge is of fundamental importance in defining the long-term impact of the disease.

Objectives: To evaluate factors associated with persistence of the joint symptoms in CHIK patients.

Methods: The CHIKBRASIL cohort is a prospective, multicenter, observational study, conducted in six research rheumatology centres from the Northeast of Brazil, and has enrolled CHIK patients with joint manifestations since April $2016 .{ }^{1}$ Data from 207 patients followed up to December 2017 were analysed.

Results: The mean age was 54.7 years, most female (90.3\%); $39.1 \%$ of the patients had a diagnosis of previous rheumatic disease (49.4\% osteoarthritis). The most frequent initial clinical manifestations were arthralgia (98.1\%), fever $(95.6 \%)$, morning stiffness $(92.3 \%)$ and arthritis $(88.9 \%)$. The first evaluation with the rheumatologist occurred at a median time of 12 weeks after the onset of symptoms; at this time the median PGA of disease by the patient was 7 and by the physician was 6 ; the median number of painful joints was 8 and of swollen joints was $3 \%$ and $75.5 \%$ of the patients had arthritis. After a median follow-up time of 37 weeks, there was complete improvement of joint symptoms in $21.7 \%$ and $18.9 \%$ of cases reported little or no improvement. The persistence of arthralgia was reported by $76.7 \%$ and arthritis by $28.1 \%$ of the patients. A significant association was found between the persistence of arthritis and the physician's general VAS $(p=0.02)$, number of painful $(p=0.002)$ and swollen $(p=0.001)$ joints, besides knees $(p=0,009)$, proximal interphalangeal $(p=0,07)$, metacarpophalangeal $(p=0,022)$, elbow $(p=0,026)$ and wrist oedema $(p=0,003)$ at the first consultation). With regard to the persistence of joint pain, associations were found with a higher initial morning stiffness time $(p=0.011)$, shoulder tendinopathy $(p=0.019)$ and tarsal pain. The factors associated with no complete improvement after the follow-up period were tarsal pain $(0,021)$ and shoulder tendinopathy.

Conclusions: In the Brazilian CHIK patients, the percentage of persistence of joint manifestations is high after 24 weeks, with a considerable number of patients maintaining arthritis, similar to other countries in Latin America. ${ }^{2}$ Significant associated factors were more severe initial symptoms, polyarthritis, polyarthralgia, shoulder tendinopathy and tarsal pain.

\section{REFERENCES:}

[1] Marques CDL, Cavalcanti N, Luna M, et al. Arthritis Rheumatol [Internet] 2016 20-nov-2016;68(S10).

[2] Chang AY, Encinales L, Porras A, et al. Arthritis Rheumatol 20172017 Dec 20. doi:10.1002/art.40384

Disclosure of Interest: None declared

DOI: 10.1136/annrheumdis-2018-eular.4885

\begin{tabular}{|l|l}
\hline SAT0389 & MRI PREDICTIVE FACTORS FOR POSITIVE CT-GUIDED \\
BIOPSY IN SUSPECTED SEPTIC SPONDYLODISCITIS
\end{tabular}

E. Chotard ${ }^{1}$, H. Jacquier ${ }^{2}$, P. Richette ${ }^{3}$, C. Rioux ${ }^{4}$, V. Joly ${ }^{4}$, E. Palazzo ${ }^{1}$, M. Forien ${ }^{1}$, G. Jelin ${ }^{1}$, Y. Yazdanpanah ${ }^{4}$, P. Dieudé ${ }^{1}$, S. Ottaviani ${ }^{1} .{ }^{1}$ Service de Rhumatologie, Hôpital Bichat, ${ }^{2}$ Service de Microbiologie, Hôpital Lariboisière; ${ }^{3}$ Service de Rhumatologie, Hôpital Lariboisière; ${ }^{4}$ Service de Maladies infectieuses et tropicales, Hôpital Bichat, PARIS, France

Background: Septic spondylodiscitis is an infection involving intervertebral disc and adjacent vertebral endplates that could lead to neurological complications. Magnetic resonance imaging (MRI) is the main imaging modality to suspect spondylodiscitis. However, MRI features predictive for septic spondylodiscitis are still lacking.

Objectives: To assess the MRI features associated with microbial pathogen detection by CT-guided biopsy among patients with suspected septic spondylodiscitis.
Methods: Between May 2007 and July 2017, we retrospectively analysed patients who underwent MRI and CT-guided biopsy for suspicion of septic spondylodiscitis. Baseline clinical and biological characteristics were collected. MRIs were analysed by one physician blinded to clinical data. The following MRI features were assessed when available: oedema or contrast-enhancement of intervertebral disk, adjacent vertebrae, epidural and paravertebral space, presence of abscess and paravertebral oedema size. A positive biopsy was defined by pathogen identification on culture or by direct microscopy examination.

Results: Fifty-one patients ( $54.9 \%$ of males, mean \pm SD age of $59.2 \pm 19.1$ years) were analysed. Lumbar spine $(n=38)$ was the most affected site. A total of 26 (51\%) patients had a CT-guided biopsy positive for a bacterial pathogen, mainly mycobacterium tuberculosis $(n=7)$ and staphylococcus aureus $(n=7)$. Disc size reduction, more than $50 \%$ of endplate oedema, loss of intradiscal cleft and abscess were the MRI findings associated with detection of bacterial pathogen by biopsy with a frequency of $100 \%, 92 \%, 81 \%$ and $50 \%$, respectively. Size of paravertebral oedema was statistically higher in positive CT-guided biopsy than those negative (20.5 \pm 12.6 vs. $11.0 \pm 9.8 \mathrm{~mm}, \mathrm{p}=0.004)$. The highest specific MRI finding for bacterial pathogen detection was the presence of paravertebral abscess $(80 \%)$.

Abstract SAT0389 - Table 1. Characteristics of the patients $(n=51)$

\begin{tabular}{lc}
\hline Male sex, $\mathbf{n}(\%)$ & $28(54.9)$ \\
\hline Age, mean \pm SD years & $59.2 \pm 19.13$ \\
Symptoms duration, mean \pm SD days & $91.7 \pm 86.58$ \\
Fever, $\mathbf{n}(\%)$ & $12(23.5)$ \\
Altered general health status, $\mathbf{n}(\%)$ & $21(41.2)$ \\
Back pain, $\mathbf{n}(\%)$ & $45(88.2)$ \\
Positive blood culture, $\mathbf{n}(\%)$ & $10(19.6)$ \\
C-reactive protein, mean \pm SD mg/L & $79.6 \pm 79.0$ \\
Neurological complications, $\mathbf{n}(\%)$ & $13(25.5)$ \\
\hline
\end{tabular}

Abstract SAT0389 - Table 2. MRI features according to bacterial pathogen detection by CT-biopsy

\begin{tabular}{|c|c|c|c|}
\hline & $\begin{array}{c}\text { Positive } \\
\text { CT-biopsy } \\
(n=26)\end{array}$ & $\begin{array}{c}\text { Negative } \\
\text { CT-biopsy } \\
(n=25)\end{array}$ & $\mathrm{p}$ \\
\hline Endplate oedema, $n$ (\%) & $26(100)$ & $24(96)$ & 0.98 \\
\hline$>50 \%$ of endplate oedema, $n(\%)$ & $24(92)$ & $17(68)$ & 0.029 \\
\hline Disc oedema ( $n=45) n(\%)$ & $25(96.2)$ & $20(80)$ & 0.145 \\
\hline Loss of intradiscal cleft $(n=30) n(\%)$ & $21(80.8)$ & $9(36)$ & 0.001 \\
\hline Epiduritis ( $n=30) n(\%)$ & 19 (73.1) & $11(44)$ & 0.067 \\
\hline Paravertebral oedema $(n=46) n(\%)$ & $23(88.5)$ & $23(92)$ & 0.317 \\
\hline $\begin{array}{l}\text { Paravertebral infiltrate size, mean } \\
\pm \mathrm{SD} \mathrm{mm}\end{array}$ & $20.5 \pm 12.6$ & $11.0 \pm 9.8$ & 0.004 \\
\hline Abscess $(n=17) n(\%)$ & $13(50)$ & $4(16)$ & 0.025 \\
\hline Endplate erosion $(n=40) n(\%)$ & $23(88.5)$ & $17(68)$ & 0.528 \\
\hline Disc size reduction $(n=47) n(\%)$ & $26(100)$ & $21(84)$ & 0.034 \\
\hline
\end{tabular}

Conclusions: Our study showed that loss of intradiscal cleft, abscess and a large endplate oedema were the best predictive factors for a positive CT-guided biopsy Size of paravertebral oedema is also associated with detection of bacterial pathogen. Physician must be aware of these MRI findings to better determine which patients should have a CT-guided biopsy.

Disclosure of Interest: None declared

DOI: 10.1136/annrheumdis-2018-eular.4169

\section{SAT0390 CLINICAL SPECTRUM OF CHIKUNGUNYA EPIDEMIC- OBSERVATIONAL STUDY FROM A TERTIARY REFERRAL CENTRE IN CENTRAL INDIA}

A. Pandey ${ }^{1}$, V. Prakash ${ }^{2}$, M. Pandey ${ }^{3} .{ }^{1}$ Rheumatology, Apollo hospitals Indore; ${ }^{2}$ Internal Medicine, MGMMC; ${ }^{3}$ Oral medicine and Radiology, My Dentist Indore, Indore, India

Background: Chikungunya virus is an alphavirus, family Togaviridae. Chikungunya fever is a mosquito born disease transmitted to humans by the bite of infected Aedes aegypti mosquitoes. An outbreak of chikungunya virus is currently ongoing in many Asian countries since January 2005. The recent outbreak and epidemic of Chikungunya fever in our state reflect the survival capability and tenacity of mosquitoes that continues to be man's biggest foes.An Observational study was conducted to evaluate epidemiological, virological and clinical features of chikungunya fever in patients presenting with acute febrile illness in our state of madhya pradesh.

Objectives: To observe the clinical features and laboratory parameters of patients coming with Chikungunya coming to our referral setup during the three months of epidemic presenting from 1 st July to 30th September 2017. 